\section{Researchers face risk of neutron shortage}

THE European neutron beam community is facing a lean time. With applications for "beam-hours" $2 \frac{1}{2}$ times the number available last year, the principal neutron source in Europe at the Institut Laue Langevin (ILL) in Grenoble is now off the air for three months, and will shut down for major repairs for at least a year beginning in August 1984. The result will be a major hiatus in neutron research programmes: although ILL officially involves only three countries (Britain, France and West Germany) the 300-400 British neutron researchers alone run around 1,000 experiments a year there, and groups from other countries join in collaborations.

In the face of this "neutron shortage", research groups are seeking neutron time elsewhere, mainly at Brookhaven, Oak Ridge and Los Alamos in the United States, where the facilities are intended largely for local users. According to one British neutron user, only "entrepreneurial types" and those with good American connections are likely to find many neutrons in 1984-85.

There are two European lights on the horizon, however. Britain's Spallation Neutron Source (SNS), under construction at the Rutherford and Appleton Laboratory in Oxfordshire and the French reactor Orphée. SNS will use an intense proton source to bombard a uranium target, producing many orders of magnitude more neutrons than ILL at high energies, a few fewer at intermediate (epithermal) energies and about the same number of low energy (cold) neutrons. Orphée is a thermal reactor, like ILL, but of about a third the power. The reactor has had teething troubles, but is just about to begin serious operation.

In Britain, SNS engineers have just demonstrated the linear injector, which accelerates hydrogen ions to $70 \mathrm{MeV}$, and the cyclotron sections, which will take protons to first $550 \mathrm{MeV}$, and later 800 $\mathrm{MeV}$. This should be giving beam (and thus neutrons) by mid-1984, just before ILL's shutdown. However, the initial neutron intensity will be low, around one-tenth of the maximum, and it will take two years to wind up the intensity fully. This is because the proton beam is of very high intensity, and any slight mistuning of the accelerator could cause the beam to irradiate internal components to intolerably high levels. Thus intensity can be increased only as tuning improves over a couple of years.

Moreover, SNS will at the outset be short of funds - ILL has been a success primarily because it began with a full complement of high quality instruments (spectrometers and so on). SNS has room for 25 instruments, operating on 18 beam lines, but it will begin with only six, with a possible seventh coming from India, where the Bhabha Atomic Research Centre has signed the only international agreement so far to work with Britain on SNS. Negotiations are also in progress with West Germany and Italy.

Moreover, at the Science and Engineering Research Council, which pays for SNS, there is a feeling that too much is being spent on neutron research.

Meanwhile, at 10-year-old ILL there are two problems: beam tubes have become embrittled through neutron exposure, and must be replaced; and a large, internal hole in a baffle plate in the reactor cooling circuit must be replaced. The French nuclear safety committee (SCIN) is considering how long ILL can continue without repairing the hole. By May this year, ILL staff hope to be given a "driving licence" to continue running with the hole unrepaired until autumn 1984. Then the repair has to be made. If it can be done through the top of the reactor, a year should be enough; if not, and the reactor has to be completely dissassembled, it could be longer.

Robert Walgate
Polish science

Talk of change

RESPONSIBILITY in Poland for applied science and its industrial applications should be transferred from the Academy of Sciences and the universities to a new state body at ministerial level, according to Dr Zdzislaw Kaczmarek, chief academic secretary of the academy. Last month, Dr Kaczmarek told the plenary meeting of the academy that the universities and the academy should retain responsibility only for basic research and that the new body should be responsible for all industryrelated research.

Such a policy would represent a total reversal of Polish science planning over the past ten years. Until 1972, Poland followed the usual Comecon model of having a "Committee of Science and Technology" at ministerial level. In that year, however, it was decided that, with 75 per cent of the research potential concentrated in the universities, the committee should be absorbed into a new Ministry of Science, Higher Education and Technology.

In 1977, at the Jablonna conference on science policy, the then academic secretary of the Polish Academy of Sciences, Dr Jan Kaczmarek (no relation), explained that the main advantage of the combined ministry was that it could increase

\title{
IRAS scans the Southern Cross
}

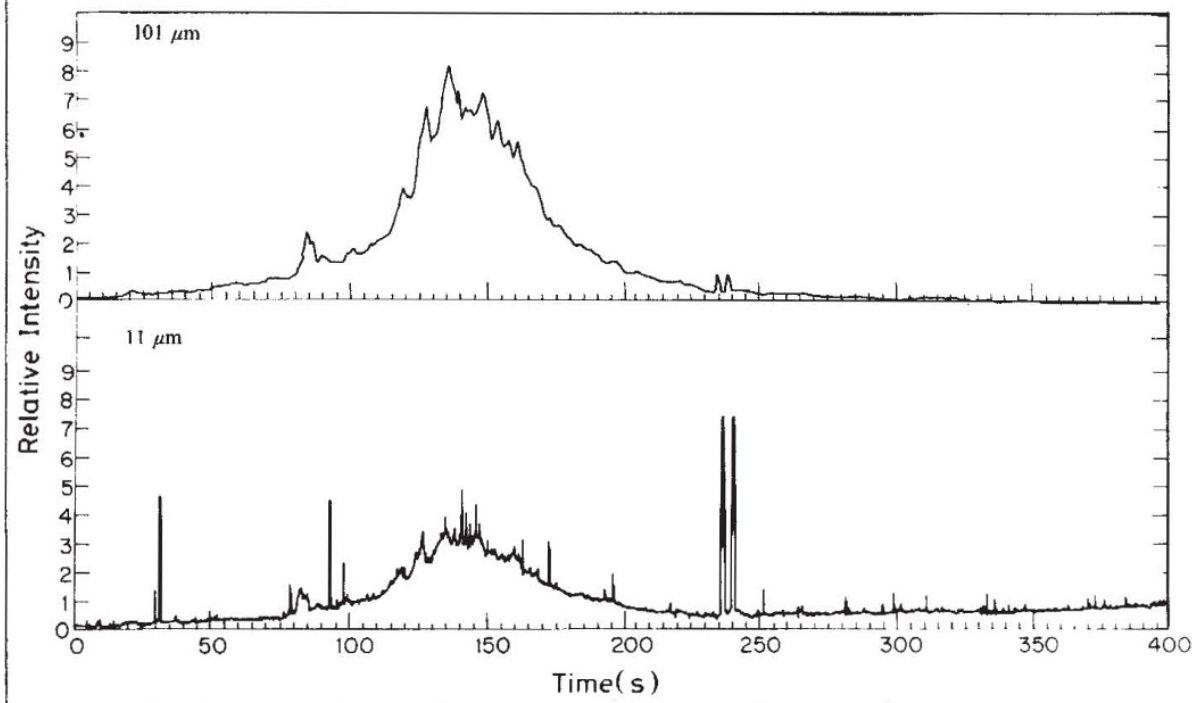

THE results of a scan of the Milky Way by the telescope of the Infrared Astronomy Satellite, launched on 26 January (see Nature 27 January, p.275). These data were obtained an hour after the protective cover of the telescope was removed. The scan covered 25 degrees of arc at $45^{\circ}$ across the plane of our Galaxy in the constellation Crux, the Southern Cross.

The upper tracing is dominated by 100 $\mu \mathbf{m}$ wavelength emission from cold dust associated with the material out of which all stars in the Galaxy are formed. The central bulge extends approximately $10^{\circ}$. The structure in the tracing is due to individual clouds of dust and molecular gas hundreds of light years across. (The two spikes on the right side of the central peak are from an internal calibration source within the telescope and indicate the relative scales of the two graphs.)

The bottom tracing shows the intensity at a wavelength of $10 \mu \mathrm{m}$ and is mainly due to emission from thousands of millions of stars. The bulge at the centre shows the densest concentration of stars; the slow increase to the right of the scan is caused by warm dust in the plane of the Solar System. The individual narrow spikes are caused by single bright or nearby stars. 
university participation in research. But he acknowledged that the combined ministry probably represented only a "transitory stage" in Polish science planning.

In practice, all science and higher learning in Poland (save a small sector of basic research accounting for no more than 10 per cent of the total science and higher education budget) had to be linked to a complex hierarchy of "problems" of the national economy. This led to researchers trying to attach their projects to as high ranking a problem as possible, and to administrative difficulties when institutes wanted to renew books or equipment used jointly by all researchers.

By autumn 1980, it was accepted that the "problems" scheme had become inoperable and should be replaced by a looser structure of applied research based on contracts between industry and the research institutes or universities. But liberalization brought two other major problems into the open - the favoured position of institutes controlled by other ministries in the competition for funds and the strict separation of the universities from the academy.

In this respect, Poland has been an exception to the pattern of most Comecon countries, including the Soviet Union, where researchers in academy institutes can and do hold university teaching posts. The Polish arrangement has, at times, proved advantageous to individual scholars. Thus some of those who lost their university posts during the 1968 purge on the grounds of political unreliability found work within the academy network, where they had no direct contact with students.

Both these issues were raised and sympathetically discussed at the Solidarity Congress in September 1981, with the reservation that Poland already had too many graduates chasing too few jobs so that combining the roles of academy researcher and university lecturer might exacerbate the situation.

A third problem, little discussed outside the academy itself, is that the academy's academic secretary, a post of ministerial rank, is ultimately responsible not to the academy but to the Prime Minister. This, it was hoped, would be remedied by new legislation, a first draft of which was due for discussion by the academy general meeting in December 1981.

That meeting was pre-empted by the declaration of martial law, since when nothing has been heard of the promised legislation. Last month, however, the journal Rzeszpospolita, which follows an orthodox political line, suggested that the new law on the academy should be drafted and passed as soon as possible on the grounds that such a law might help to break down mistrust between the academy and the authorities, inducing Polish scholars to end their current stance of "internal emigration" - a euphemism for noncooperation with the authorities and the government.

Vera Rich

Ohio radiotelescope

\section{Seeing stars or golf balls?}

\section{Washington}

OHIO State University was abruptly informed last month that the land beneath its radio telescope - the fourth largest in the United States - is about to become the site of the Deleware Country Club's new golf course. University officials, who were apparently taken completely by surprise, are trying to work out a temporary arrangement with the country club, but there seems to be little chance that the telescope will be allowed to remain for more than five years.

Dr John Kraus, director of the radio observatory, calls the situation "a great scientific tragedy"'. An all-sky search for $21-\mathrm{cm}$ wavelength sources, completed two years ago at the observatory, catalogued 20,000 objects, including many undiscovered quasars, some of them the most distant quasars yet seen. At present, the chief work of the observatory is its participation in the National Aeronautics and Space Administration (NASA) search for extraterrestrial intelligence.

Although the observatory was built by Ohio State University (with funds from the National Science Foundation), the land it sits on was provided by Ohio Wesleyan University. Under the terms of this joint venture, the universities were to share in the use of the observatory, but Ohio Wesleyan's interest has apparently waned in the 25 years since it was built. Last October, Ohio Wesleyan offered the country club an option to buy a 250 -acre parcel and that includes the 100 acres currently leased by the club and 150 additional acres - among them the 15 acres occupied by the radio telescope.

According to Larry Thompson, assistant to the president of Ohio State, the university was told only after a contract for the sale had been signed.

A spokesman for Ohio Wesleyan says that its president, Thomas Wenzlau, had in fact discussed the sale of the land with the former provost of Ohio State two years ago, and that Ohio State "indicated they wanted to discontinue operation of the telescope by 1984 ".

"Ohio State showed no interest in

The threatened telescope

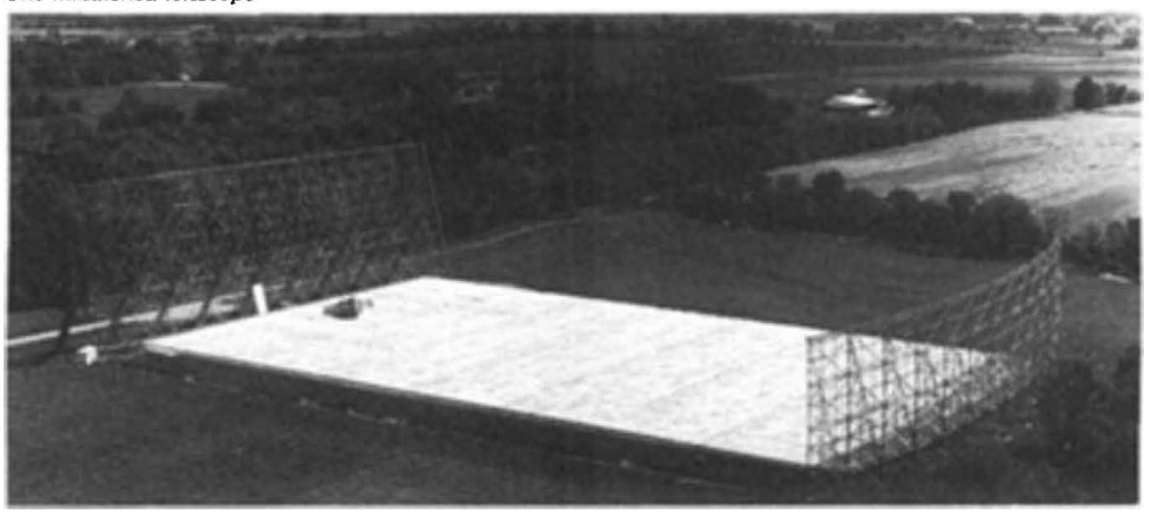

buying the property", he says. The spokesman suggested that the cause of the confusion may be the change in the Ohio State administration - both the provost and the president have left since that discussion took place. The spokesman adds that no Ohio Wesleyan faculty members now use the observatory and "we know of only one Ohio Wesleyan student who's used it in the last 10 years"

Ohio State officials have had one meeting with representatives of the country club to see if the telescope could remain. Earlin Harris, a member of the club who is involved in the negotiations, says, "I think all the issues will be resolved within a month of so", permanent solution. Dr Howard Sachs, associate provost at Ohio State, concedes that the university is in principle resigned to closing down the observatory. "The major problem is that we have only two faculty [members] right now who are intimately involved in its operation", he says. Kraus, the director, is one; he is a professor emeritus. The other is Dr Robert Dixon of the computer sciences department, who is not a full-time astronomer. The design of the telescope, which Kraus says provided the greatest aperture per unit cost, is tailored to the task of scanning the entire sky - making it of only limited use for most radioastronomy research.

Replacing the telescope would require an investment of $\$ 5$ million, according to Kraus; transporting it to a new location would be nearly as expensive. Sachs says that from the university's point of view, five years "would be a reasonable time" to try to keep the observatory open.

The country club has its own reasons for wanting to get rid of the observatory - and not just its plans to expand its nine-hole course to 18 holes. Sachs says the purchasers plan eventually to build residential units along the fairways. And the telescope, he admits, "is not the most desirable thing to have in your backyard. It looks like a couple of drive-in movie theaters that went out of business",

Stephen Budiansky
But the university does not expect a 